\title{
A TECHNIQUE OF METABOLIC BALANCE STUDY IN THE NEWBORN BABY
}

\author{
BY \\ L. H. STEVENS, ELIZABETH A. HUGHES and A. W. WILKINSON \\ From the Department of Paediatric Surgery, The Institute of Child Health and The Hospital \\ for Sick Children, Great Ormond Street, London
}

(RECEIVED FOR PUBLICATION JUNE 14, 1962)

The nutritional requirements of a living body can be studied by the method of metabolic balance, the intakes of certain chosen constituents of the diet being measured and compared with the output of these elements in urine and faeces or loss in discharges during the same period of time. There are a number of well-recognized disadvantages to this method which arise both from difficulties in its practical application and from the different rates of discharge from the body after formation of urine and faeces. In addition, in studies lasting more than a few days, the accumulated daily errors of collection and estimation may become so large as to be misleading, and it is difficult to maintain steady environmental conditions throughout a prolonged period of observation. Although the requirements of the growing baby have been studied extensively by this method, very few serial observations have been made during the establishment of feeding in the first two weeks after birth (Smith, 1959; Smith, Yudkin, Young, Minkowski and Cushman, 1949; Butterfield, Lubchenco, Bergstedt and O'Brien, 1960). In the past urine and faeces have usually been collected by methods that imposed severe restrictions on the normal activity of the baby, so that the duration of the observations has been limited to only a few days; it seems likely also that some of the methods of physical restraint that have been used during earlier metabolic studies have increased energy expenditure. As our objective was to study for 10 to 14 days the metabolic behaviour of newborn babies who had been subjected to major abdominal and thoracic operations, we had to devise accurate methods of collection that did not involve interference with the normal activity of the baby. We tried to use polythene bags which were fixed on over the vulva or penis for the collection of urine and over the anus for the collection of faeces, but found that the adhesive irritated the skin of most children so badly that this method could seldom be used for more than four or five days. The methods we have adopted allow also the clinical behaviour of the baby to be recorded and compared with the metabolic changes (Wilkinson, Stevens and Hughes, 1962).

\section{General Considerations}

Three groups of babies have been studied. In the first group were normal babies born uneventfully, in the second babies suffering from foetal distress and in the third babies who had been subjected to major operations for a congenital abnormality of the alimentary tract. All the babies in the first group were studied in the open nursery and were clad in the usual way as were all the second group, except two who were nursed for a time in incubators. All the babies in the third group were nursed and studied for most of the time in incubators. Thus in each group the environmental conditions were those which would normally have held even if the babies had not been under study. The temperature of the nursery was maintained at $70^{\circ} \mathrm{F} .\left(21^{\circ} \mathrm{C}\right.$. $)$, and records were kept of the rectal temperatures of the babies and of room temperature. The babies who were recovering from operations were nursed nude in the incubators, the internal temperature and humidity of which were regulated within narrow limits and recorded with the rectal temperature of the baby. The interest, co-operation and help of the ward sisters and their nursing staff are indispensable, but success ultimately depends on the persistent and personal supervision of the collections by members of the team, who must be prepared to devote a considerable part of their time solely to this aspect of the study.

\section{Metabolic Balance Procedure}

Intake. During the first two weeks of life a very large proportion of the milk intake is retained. The intake should therefore be accurately measured and its composition directly estimated whenever possible during balance studies at this time of life. We were 
able to do this in all cases except two children who were breast fed by their mothers for a part or for the whole of the time they were being studied. These children were weighed before and after each feed and their intake was calculated from the composition of breast milk shown in standard tables (Spector, 1956). The range in these tables is so wide that large discrepancies might result from the general use of these tables in metabolic work, but our own estimations of the composition of breast milk agiee well with those of Macy and her colleagues (Nims, Macy, Hunscher and Brown, 1932). In the case of babies who were fed on expressed breast milk a $90-\mathrm{ml}$. sample of the well-mixed daily supply of expressed breast milk was taken and deep frozen in polythene bottles for analysis. When babies were fed on reconstituted cows' milk a duplicate set of feeds for analysis was provided by the hospital milk kitchen.

When, before feeds were begun, babies were given water, glucose solution or saline, samples of these fluids were taken for analysis as their mineral content was found to vary widely. When antibiotics were administered these also were analysed and allowance made for their mineral content in computing the balance.

\section{Output}

Urine. Urine was collected in a piece of Paul's tubing, $30 \mathrm{~cm}$. in length, which was fixed to the penis with $\frac{1}{2}$-in. adhesive strapping. The distal end of the tubing was knotted during collection; the tubing was untied and emptied whenever urine was seen within it and was also drained at the end of each six-hour period. Before use the Paul's tubing was thoroughly washed with ion-free water to remove all traces of talc dressing on its surface. Ion-free water, obtained by the passage of distilled water through an ion exchange resin, was used throughout. The urine was measured immediately it was removed from the tubing and was then stored under paraffin in $4 \mathrm{oz}$. (120 ml.) polythene bottles in a deep freeze until analysed, two drops of $1 \%$ merthiolate solution being used as preservative. Polythene bottles were used for the storage of milk and urine to avoid leaching of sodium from the containers. Moreover, glass containers cannot be deep frozen without a high rate of breakage. All containers were washed with ion-free water before they were used.

Stools. Stools were collected on cellophane or polythene squares placed inside the napkin; the square and stool were put into small $33-\mathrm{ml}$. widemouthed perspex containers with clip lids and were then frozen; on removal from the deep freeze the frozen stool can be readily shaken off the square. When there was leakage of urine or loss of stool onto the napkin or bed linen, the linen or napkins were soaked out over night in a known volume (approximately $250 \mathrm{ml}$. per napkin) of ion-free water and the washings were preserved. Five different kinds of napkins and sheeting were used; standard Turkish towelling, smooth Harington squares, Bowater Scott paper towelling, sheets of wool and cellulose, or sheets of cellulose backed with paper and polythene. Since it was impossible to make blank estimations before use on the nondisposable types of napkin or sheeting it was necessary to establish the standard deviation for the content of the elements which were being estimated. It was found (Table 1) that the sodium content of three materials was high and that the potassium and chloride content were also high in one of these. The quantities present were considerably greater than the minimal amount detectable by the methods of analysis employed. It was found also that other properties of the disposable material affected the usefulness and ease with which they were handled in the laboratory. The best of these was the paper towelling. When there is free choice, however, we recommend Harington squares which have been rinsed in ion-free water and dried before use.

It will be evident from Table 1 that there are extremely small quantities of sodium, potassium and chloride in the paper and cotton napkins. Even such small quantities are important in balance studies on the newborn child and proper allowance must be made for them. The average content of $1.1 \mathrm{mEq}$ per litre of washings from four rough napkins may be equal to the entire daily output of sodium in the urine and the standard deviation alone might exceed in amount $10 \%$ of the intake and thus affect the balance; in fact with the exception of one type of material this happened on only one or two occasions. The potassium content was only one-sixtieth or less of that of sodium and there were only traces of chloride except in the woolcellulose fabric and of nitrogen in the paper towelling. During the first four days after birth there was seldom any difficulty in collecting all the urine and faeces without leakage or loss and the losses of urine throughout were minimal. Urine losses were most common during the two or three days of increased activity towards the end of the first week.

As far as possible the stools were divided according to their physical appearance into meconium, transitional and mature. It might be necessary and convenient to subdivide such periods but they were never combined. Markers were not used in these balances during the first fortnight of life. 
TABLE 1

\begin{tabular}{|c|c|c|c|c|c|c|c|c|c|c|c|c|}
\hline \multirow{2}{*}{\multicolumn{4}{|c|}{ Material }} & \multicolumn{3}{|c|}{ Sodium } & \multicolumn{3}{|c|}{ Potassium } & \multicolumn{3}{|c|}{ Chloride } \\
\hline & & & & \multirow{2}{*}{$\frac{\substack{\text { Mean } \\
*}}{1 \cdot 13}$} & \multirow{2}{*}{$\frac{\begin{array}{c}\text { Standard } \\
\text { Deviation }\end{array}}{0 \cdot 20}$} & \multirow{2}{*}{$\begin{array}{c}\text { Number } \\
81\end{array}$} & \multirow{2}{*}{$\frac{\substack{\text { Mean } \\
*}}{0.01}$} & $\begin{array}{l}\text { Standard } \\
\text { Deviation }\end{array}$ & Number & $\underset{*}{\text { Mean }}$ & $\begin{array}{l}\text { Standard } \\
\text { Deviation }\end{array}$ & Number \\
\hline Turkish towelling & . & $\ldots$ & $\cdots$ & & & & & & 81 & Nil & & 10 \\
\hline Harington squares & & $\cdots$ & $\cdots$ & $0 \cdot 60$ & $0 \cdot 19$ & 80 & $0 \cdot 01$ & & 80 & Nil & & 9 \\
\hline Wool and cellulose & & . & $\cdots$ & $1 \cdot 34$ & $0 \cdot 25$ & 27 & $1 \cdot 55$ & $0 \cdot 29$ & 27 & $0 \cdot 86$ & $0 \cdot 21$ & 27 \\
\hline $\begin{array}{c}\text { Cellulose backed } \\
\text { polythene }\end{array}$ & $\begin{array}{l}\text { with } \\
\cdots\end{array}$ & $\begin{array}{c}\text { paper } \\
\cdots\end{array}$ & $\begin{array}{r}\text { and } \\
\ldots\end{array}$ & $>2 \cdot 5$ & & 3 & 0.04 & & 14 & Nil & & 9 \\
\hline Paper towelling & $\ldots$ & . & $\ldots$ & $0 \cdot 19$ & & 9 & 0.03 & & 9 & $0 \cdot 33$ & & 9 \\
\hline
\end{tabular}

* $\mathrm{mEq} /$ litre of washing water.

It should be recognized that the primary object is to collect the stool on the polythene square inside the napkin but the total mineral content of the stool may be high in relation to the daily intake and the accurate measurement of losses from the square is essential if a precise balance is to be obtained. This is particularly important when the baby is being fed on reconstituted cows' milk which contains more sodium and potassium than human milk.

Vomit, Aspiration and Drainage. Few babies who were fed on breast milk regurgitated or vomited, but as a precaution paper towels were placed beneath the head and shoulders. Fluid aspirated from the stomach was collected separately in a polythene container and deep frozen. The same procedure was followed for fluid removed by drainage tubes. When large quantities of body fluids or exudate were lost into dressings, the dressings were analysed. All these losses by aspiration, leakage or drainage were included in the final data.

Blood Loss. Blood loss at operation was measured by weighing the discarded swabs together with any blood in the sucker tubing and reservoir. The total operative loss did not often exceed 25-30 ml., but all losses of more than $15 \mathrm{ml}$. were replaced immediately by transfusion.

Blood. If possible daily specimens of blood were obtained by heel prick and in a few instances by vein puncture. Micro-methods of analysis were used throughout. Heparin was used as an anti-coagulant.

Weight. The babies were weighed nude at the same hour each day before being fed. It was not possible, however, to follow Benedict's (1915) recommendation regarding the emptying of the bowel and bladder before weighing. Weights were measured in ounces to the nearest $0 \cdot 25 \mathrm{oz} .(7 \cdot 3 \mathrm{~g}$.) and then were converted to $\mathrm{kg}$. After operation allowance was made for the dressings when they were used. Drainage and infusion tubing was suspended during the weighing.
Clinical Observation. Close clinical observation repeated at short intervals is essential if the metabolic changes are to be related to clinical behaviour. Particular attention was paid to the following features; the character and rate of respiration, the general activity and the type of movements made, the frequency and nature of the sucking, bowel sounds, pulse rate and the colour, temperature and response to blanching of the skin of the extremities.

Chemical Analysis of Specimens. Samples of breast milk, urine and nappy washings were analysed daily for sodium, potassium, chloride, nitrogen and phosphorus. Sodium and potassium estimations were done on six-hourly urine specimens which were then pooled into 24-hour lots for nitrogen and chloride determinations. The stool collections were bulked for two or three days for analysis as meconium, transitional or faecal material. Before analysis the samples of milk, stools and nappy washings containing faeces were homogenized with a Silverson laboratory emulsifier.

Sodium and potassium estimations were made in an E.E.L. flame photometer and chloride by Volhardt's method, after digestion if necessary with nitric acid. Nitrogen was estimated by the microKjeldahl technique and phosphorus by the molybdate procedure, the homogenates being first digested with sulphuric acid.

\section{REFERENCES}

Benedict, F. G. (1915). A Study of Prolonged Fasting. Carnegie Institute of Washington, Washington.

Butterfield, J., Lubchenco, L. O., Bergstedt, J. and O'Brien, D.(1960). Patterns in electrolyte and nitrogen balance in the newborn premature infant. Pediatrics, 26, 777.

Nims, B., Macy, I. G., Hunscher, H. A. and Brown, M. (1932). Human milk studies. Daily and monthly variations in milk components as observed in two successive lactation periods. Amer. J. Dis. Child., 43, 1062.

Smith, C. A. (1959). The Physiology of the Newborn Infant, 3rd ed. Thomas, Springfield, Illinois.

-, Yudkin, S., Young, W., Minkowski, A. and Cushman, M. (1949). Adjustment of electrolytes and water following premature birth. Pediatrics, 3, 34.

Spector, W. S. (ed.) (1956). Handbook of Biological Data, p. 50. Saunders, Philadelphia and London.

Wilkinson, A. W., Stevens, L. H. and Hughes, E. A. (1962). Metabolic changes in the newborn. Lancet, 1, 983. 